University of Nebraska - Lincoln

DigitalCommons@University of Nebraska - Lincoln

Uniformed Services University of the Health

Sciences

U.S. Department of Defense

2011

\title{
The case for simulation as part of a comprehensive patient safety program
}

Cynthia H. Argani

Johns Hopkins School of Medicine

Melissa Eichelberger

Johns Hopkins Bayview Medical Center

Shad Deering

The Uniformed Services University of the Health Sciences

Andrew J. Satin

Johns Hopkins School of Medicine

Follow this and additional works at: https://digitalcommons.unl.edu/usuhs

Part of the Medicine and Health Sciences Commons

Argani, Cynthia H.; Eichelberger, Melissa; Deering, Shad; and Satin, Andrew J., "The case for simulation as part of a comprehensive patient safety program" (2011). Uniformed Services University of the Health Sciences. 31.

https://digitalcommons.unl.edu/usuhs/31

This Article is brought to you for free and open access by the U.S. Department of Defense at DigitalCommons@University of Nebraska - Lincoln. It has been accepted for inclusion in Uniformed Services University of the Health Sciences by an authorized administrator of DigitalCommons@University of Nebraska Lincoln. 


\title{
The case for simulation as part of a comprehensive patient safety program
}

\author{
Cynthia H. Argani, MD; Melissa Eichelberger, MS, RNC; Shad Deering, MD; Andrew J. Satin, MD
}

$\mathrm{M}$ edical simulations attempt to recreate events or scenes in clinical practice that are considered important to know or understand. Simulator refers to all the technologies used to imitate various specific tasks. High-fidelity simulators suggest close reproduction of the actual clinical environment. Low-fidelity implies an incomplete or rudimentary clinical environment. Low-fidelity simulators are used commonly in obstetric training and include pelvic manikins, whereas examples of high-fidelity simulators include virtual reality robotic or laparoscopic simulators.

The growing interest in simulations for obstetrics and gynecology stems from contemporary changes in medical education and concerns for patient safety. The potential benefits are manifold. For residents, simulation offers several unique opportunities. Obstetric residents may learn new skills in a safe and controlled environment without the awkward audience of patients and family members. Simulations enable uniform exposure of residents to rare events that they may not encounter otherwise during training. They provide an opportunity to rehearse and learn from mistakes without harming patients. In gynecologic surgery, the new teaching model

From the Departments of Gynecology and Obstetrics, The Johns Hopkins School of Medicine (Drs Argani and Satin), Obstetrics and Gynecology, Johns Hopkins Bayview Medical Center (Drs Argani and Satin and Ms Eichelberger), Baltimore, MD; The National Capital Area Simulation Center and the Department of Obstetrics and Gynecology, The Uniformed Services University of the Health Sciences, Bethesda, MD (Dr Deering).

Received July 22, 2011; revised Sept. 13, 2011; accepted Sept. 13, 2011.

The authors report no conflict of interest.

Reprints not available from the authors.

0002-9378/\$36.00

(C) 2011 Mosby, Inc. All rights reserved.

doi: 10.1016/j.ajog.2011.09.012

Simulation in obstetrics allows us to practice in a safe environment. Simulations can improve the performance of individuals and obstetric teams. The evidence is overwhelming that, with simulated practice, obstetricians improve their technical and communication skills. Evidence is emerging that simulation ultimately may improve clinical outcomes. It stands to reason that simulation in obstetrics should be incorporated into comprehensive patient safety programs.

Key words: patient safety, simulation, skill

includes learning basic surgical skills, practicing on a model, watching videos and observing in the operating room, and ultimately performing a surgical procedure with feedback and evaluation. Simulation allows for standardized objective evaluation of performance. For experienced physicians, simulation programs can serve as refresher courses and can introduce new technical advances. With proper validation, they may be used eventually to demonstrate proficiency and to help with the credentialing and certification processes. Programs may also be used to help ease the reentry process for providers who have taken a clinical leave of absence. From a hospital's standpoint, simulation easily incorporates into comprehensive safety initiatives. ${ }^{1}$ Programs can help reinforce teamwork and communication skills and can help to identify system issues that impair optimal patient care. Thus, simulation programs can improve not only performance of individuals but also obstetric teams. This overview not only will make the case for simulation programs but also will provide insight into the challenges with the initiation of programs and potential resources for assistance in program development.

\section{Simulation development}

All simulation programs are not created equal. Poorly constructed and executed simulations can reinforce bad habits. Unfortunately, many institutions spend large sums of money on simulation equipment before they develop their program. The simulator, no matter how sophisticated, does not run itself. Simulation is but one part of an education or safety program, not the focus of the program. The design of simulations must take into account who the learners are and what they must learn. Simulations that are designed to teach obstetricians the maneuvers to ensure delivery when a shoulder dystocia is encountered will be designed differently than simulations to improve the labor and delivery teams' response to a shoulder dystocia on the unit. Strong programs include didactic, simulation, and debriefing sessions.

The didactic portion helps to ensure that participants have baseline knowledge about the subject matter. When done before the simulation, it helps to allay the participants' fears that they will look foolish during the simulation. When done after the simulation, participants have the additional benefit of practical experience to apply to the didactic knowledge. The simulation portion allows the attendees to have practical hands-on experience. Adult learners, in particular, often retain more from doing than from hearing a lecture. Simulations can focus not only on particular skills, such as a forceps delivery, but also on communication and team-building exercises. Shoulder dystocia drills often combine both practice of specific maneuvers and exercise in communication skills.

The debriefing portion may serve the most important role. It provides a framework for open communication between 


\section{TABLE 1}

\section{Obstetric scenarios}

\begin{tabular}{|c|c|}
\hline Institution & Scenario \\
\hline \multirow{6}{*}{$\begin{array}{l}\text { American College of Obstetricians and Gynecologists } \\
\text { Consortium }\end{array}$} & Shoulder dystocia \\
\hline & Eclampsia \\
\hline & Postpartum hemorrhage \\
\hline & Vaginal breech \\
\hline & 4th-degree laceration repair \\
\hline & Operative vaginal delivery \\
\hline \multirow[t]{6}{*}{ Society for Maternal-Fetal Medicine } & Invasive fetal needle diagnostics \\
\hline & Invasive fetal therapy \\
\hline & Cardiopulmonary arrest \\
\hline & Thyroid storm \\
\hline & Diabetic ketoacidosis \\
\hline & Critical care obstetrics \\
\hline \multicolumn{2}{|c|}{$\begin{array}{l}\text { Obstetric scenarios that the American College of Obstetricians and Gynecologists and the Society for Maternal-Fetal Medicine } \\
\text { deemed worthy of simulation development. }\end{array}$} \\
\hline \multicolumn{2}{|c|}{ Argani. Simulation in a comprehensive patient safety program. Am J Obstet Gynecol 2011.} \\
\hline
\end{tabular}

multiple members of the team without the stress and pressure of defending a poor patient outcome. If the simulation is recorded digitally or filmed, it renders an unbiased look at what occurred. Often, participants will be surprised at their perception of what happened vs the recorded documentation. The debriefing allows the attendees both to evaluate their own performance and to discuss system issues that impair optimal outcome. The latter is particularly important when drills are performed in actual clinical spaces. As an example, we performed an on-site drill of a patient with eclampsia on our labor and delivery unit. Our simulated patient's postpartum course was complicated by magnesium toxicity. During the drill, we identified that calcium gluconate had been removed from our automated drug dispersal system. As a result of the drill, this issue was rectified before a poor patient outcome occurred. A recent drill that involved a preterm delivery on our antepartum ward uncovered that our precipitous delivery kit lacked scissors, that there was not an immediately available neonatal Ambu bag, and that a radiant warmer was not available readily. Thus, these unit-based drills not only may thwart a potentially bad outcome but also may help to establish a culture of safety where a diverse group of personnel is empowered to identify and reduce risks. $^{2}$

When initiating a simulation program, the "Five Ws" can help guide its development. First, the "who" must be identified. Is the program geared to house staff, experienced physicians, or the entire team that is involved in patient care? The goals of the simulation project become clear once the targeted audience is established. In general, junior staff members will gain more from simulation than senior staff members. Goffman et $\mathrm{al}^{3}$ evaluated the use of a shoulder dystocia simulation program. The study involved both residents and attending staff members. A pretest was done, followed by a training session and posttest. Although only the residents showed significant improvement in procedural skills after the training session, both residents and attendings improved communication skills after simulation. Dupuis et $\mathrm{al}^{4}$ focused on correct usage of forceps. They designed a high-fidelity simulation model that tracked the tip of the forceps blade during placement. They studied both junior and senior providers and found that senior providers were more likely to place forceps cor- rectly. Importantly, simulation training by junior providers resulted in improved placement of forceps. ${ }^{5}$

Second, the "what" must be considered. There are a plethora of simulation programs from which to choose. Table 1 provides a partial outline of available topics that have been suggested by the American College of Obstetricians and Gynecologists (ACOG) Simulation Consortium and the Society for MaternalFetal Medicine Simulation Subcommittee. In addition to the choice of a topic, the type of simulation must be considered. Simulation projects can encompass actors, low-fidelity models, and high-fidelity models. An actor may be perfectly sufficient for an on-site eclampsia drill, whereas training for robotic surgery may require a more sophisticated high-fidelity simulator. Many simulations use hybrids or various combinations of lowand high-fidelity simulators and standardized patients. One group compared a low-fidelity model for shoulder dystocia (doll and pelvis) with a high-fidelity model that included feedback on the force that was used to effect delivery. ${ }^{6}$ At baseline, $43 \%$ of the participants were able to deliver the fetus. Those who underwent the low-fidelity training were able to deliver the simulated fetus $72 \%$ of the time after training, compared with $94 \%$ of the high-fidelity group. Simulation participants in the high-fidelity group also used less total applied force to deliver the fetus. Models that track the amount of traction that is used at the time of forceps delivery have also been developed. Leslie et $\mathrm{al}^{7}$ demonstrated an improved use of the correct forces after simulation training. Biomedical engineers at Johns Hopkins developed a simulator that measures strain on the fetus' brachial plexus while undergoing shoulder dystocia. Researchers postulate that feedback of this information to obstetricians who perform simulated shoulder dystocia drills may lead to the achievement of vaginal delivery and the reduction of strain on the brachial plexus.

Third, the "where" must be determined. Deciding on location may be dependent on space and equipment constraints, however, on-site and off-site drills may achieve different aims. Off- 
site drills may have the advantage of having the participants' undivided attention without competing clinical responsibilities. They can be scheduled to ensure that all staff participates in a simulation session. On-site drills not only provide valuable learning opportunities but also can test hospital systems and response times. For instance, during one practice session at our institution, it became apparent that the code team did not know where the Fetal Assessment Center was located. As a result, we have improved signage in the hospital to help prevent a similar event in the future. Ellis et $\mathrm{al}^{8}$ compared the effectiveness of training on-site vs at a simulation center for the management of eclampsia. The on-site training consisted of patient-actors and basic manikins, although the simulation center had an advanced patient simulator model.

Both groups underwent a didactic course as well. The simulations were repeated within 1-3 weeks of training. Both groups showed similar improvement in completing the expected tasks in a timely fashion. The authors suggested that the cost of using the simulation center, compared with the unit, was not justified by the measured outcomes.

Fourth, the "when" must be established. Although it is tempting to schedule sessions when staff members are already working, often the participants will be distracted by competing responsibilities. Depending on the size of the unit, drills may have to be cancelled because of lack of room when the patient volume is high. Ideally, simulations would occur during both scheduled and unscheduled sessions. Scheduled sessions ensure that all staff members gain exposure and are able to attend the entire program without interruptions. Impromptu on-site simulations test the system and allow participants to reinforce good practices in a realistic setting. We recommend compiling suggested drills with teaching points and a debriefing tool that is left in an accessible place on the unit. This resource will enable the charge nurse or attending physician to initiate drills that include off-shifts when there is downtime and will help to maximize involvement. Another question

\section{TABLE 2}

\section{Classification system for the characterization of evidence for simulation}

\begin{tabular}{llll}
$\begin{array}{l}\text { Evidence } \\
\text { level }\end{array}$ & Simulator & Publication & Assessment tool \\
\hline 1 & Inadequate & None & Not validated \\
\hdashline 2 & $\begin{array}{l}\text { Average, not high-fidelity or not } \\
\text { commercially available }\end{array}$ & None & Not validated \\
\hdashline 3 & Adequate simulator & Yes & Not validated \\
\hdashline 4 & Adequate simulator & Yes & Resident level validation \\
\hdashline 5 & Adequate simulator & Yes & Staff level validation
\end{tabular}

Argani. Simulation in a comprehensive patient safety program. Am J Obstet Gynecol 2011. that arises is how often simulations must be repeated to ensure retention of knowledge. Crofts et al ${ }^{9}$ examined retention of skills after a shoulder dystocia training program. In addition to simulation practice, a didactic session was given. At baseline, $49 \%$ of the participants were able to deliver the fetus. Repeat testing was performed at 3 weeks with $82 \%$ success, at 6 months with $84 \%$ success, and at 1 year with $85 \%$ success. Maslovitz et $\mathrm{al}^{10}$ held a program for the management of eclampsia, postpartum hemorrhage, shoulder dystocia, and breech extraction. Follow-up testing that was performed at least 6 months after the training showed sustained improvement. Thus, how often simulations must be repeated is not clear and may very well vary with the clinical scenario that is being addressed.

Fifth, the "why" must be investigated. To be successful with any project, clear expectations should be set. These must

\section{TABLE 3}

The current state of simulation in obstetrics

\begin{tabular}{|c|c|c|c|c|}
\hline Procedure & $\begin{array}{l}\text { Adequate } \\
\text { simulator } \\
\text { available }\end{array}$ & Publications & $\begin{array}{l}\text { Current } \\
\text { level of } \\
\text { evidence }^{a}\end{array}$ & Comment \\
\hline Eclampsia & Yes & Yes & 2 & $\begin{array}{l}\text { Best available simulator } \\
\text { addition has to be installed } \\
\text { separately }\end{array}$ \\
\hline Breech delivery & Yes & Yes & 4 & $\begin{array}{l}\text { Different models to choose } \\
\text { from }\end{array}$ \\
\hline Postpartum hemorrhage & Yes & Yes & 4 & $\begin{array}{l}\text { Good for basic hemorrhage } \\
\text { drills, more needed for } \\
\text { advanced evaluation }\end{array}$ \\
\hline Amniotic fluid embolism & No & No & 2 & $\begin{array}{l}\text { Issues with having high } \\
\text { enough fidelity with female } \\
\text { birthing manikin }\end{array}$ \\
\hline Shoulder dystocia & Yes & Yes & 5 & $\begin{array}{l}\text { Best validated/studied } \\
\text { obstetric simulation at } \\
\text { present }\end{array}$ \\
\hline Operative vaginal delivery & Yes & Yes & 4 & $\begin{array}{l}\text { Allows for counseling and } \\
\text { procedural skills to be } \\
\text { evaluated }\end{array}$ \\
\hline Cesarean delivery & No & No & 1 & $\begin{array}{l}\text { No commercially available } \\
\text { simulator available }\end{array}$ \\
\hline
\end{tabular}

a Deering; presented at Simulation Forum, 2011 SMFM annual meeting

Argani. Simulation in a comprehensive patient safety program. Am J Obstet Gynecol 2011. 


\section{TABLE 4}

\section{Resources for the development of obstetric simulation programs}

\begin{tabular}{|c|c|c|}
\hline Organization & Program & Email address \\
\hline \multicolumn{3}{|l|}{ Academic } \\
\hline $\begin{array}{l}\text { American College of Obstetricians } \\
\text { and Gynecologists }\end{array}$ & Simulation Consortium & ebukevicz@acog.org \\
\hline Society for Maternal-Fetal Medicine & Education Committee \& Simulation Subcommittee & shad.deering@us.army.mil \\
\hline Johns Hopkins Hospital & Johns Hopkins Simulation Center & hopkinsmedicine.org/simulation.center \\
\hline Mayo Clinics & Multidisciplinary Simulation Center & mayo.edu/simulation center \\
\hline Stanford University & $\begin{array}{l}\text { Center for Advanced Pediatric \& Perinatal } \\
\text { Education }\end{array}$ & cape.Ipch.org \\
\hline Uniformed Services University & National Capital Area Medical Simulation Program & simcen.usuhs.edu \\
\hline \multicolumn{3}{|l|}{ Commercial } \\
\hline Adam, Rouilly Limited & & adam-rouilly.co.uk \\
\hline Gaumard Scientific & & gaumard.com \\
\hline Laerdal & & laerdal.com \\
\hline Limbs and Things & & limbsandthings.com \\
\hline Medical Education Technologies & & meti.com \\
\hline Simulaids, Inc & & simulaids.com \\
\hline
\end{tabular}

Argani. Simulation in a comprehensive patient safety program. Am J Obstet Gynecol 2011.

be shared with the staff members so that they also understand the purpose of the simulation program. In general, resistance will be encountered with new initiatives. Unit drills should be unit goal specific. Nurses and physicians on our unit targeted reduction in the time from decision to perform cesarean section to delivery. Team simulations were designed subsequently and included a prolapsed umbilical cord in various areas of our hospital and clinics. Most people in health care genuinely wish to provide good care but may not see immediately the value of a simulation program. At one of our drills, one of the nurses burst into tears because she felt unprepared and was startled and embarrassed to be videotaped without previous warning. By setting mutual goals early on, participants will better understand the potential benefits of the project. The successful reduction of time from decision to cesarean delivery after simulated exercises sparked interest in further expansion of simulated drills at our institutions.

\section{Obstetric simulations}

In 2007, ACOG formed a task force on Simulation for Resident Education and a task force on Reentry. Both task forces rec- ognized simulation as a valuable education component for graduate and postgraduate education. The ACOG Simulation Consortium subsequently was formed. The group was created to provide simulationbased obstetric and surgical skills training for obstetrics/gynecology residents. Its mission is to develop and implement unique simulation-based curricula to augment traditional procedural-oriented education.

The group identified a variety of simulation scenarios that were important for resident education and included management of shoulder dystocia, postpartum hemorrhage, eclampsia, vaginal breech delivery, amniocentesis, and fourth-degree laceration repair. The group shared and refined learning objectives, skills to be taught, simulation scenarios, and evaluation tools. Recently, this group formed a subcommittee to perform research into best simulation practices. In 2010, the Society for MaternalFetal Medicine held a postgraduate course on simulation for maternal-fetal medicine. Similar to simulation for obstetric residents, it focused on either skill in which patient availability was limited or rare critical events. Simulations that were reviewed included chorionic villous sampling and other invasive needle procedures, breech extraction of a second twin, management of thyroid storm, diabetic ketoacidosis, and cardiopulmonary arrest in pregnancy (Table 1). Thus, obstetric simulation has been used by a broad spectrum of health care providers from medical students to residents to postgraduate fellows to experienced obstetricians and subspecialists.

\section{Simulation efficacy}

The current state of simulation in obstetrics is evolving rapidly. Many commercial simulators and home-grown simulators are being used throughout the United States. Critics have been quick to point out that there is not sufficient evidence to support the notion that simulation uniformly improves patient outcomes. A current PubMed search with the key words "simulation" and "obstetrics" identified 318 peer-reviewed Englishlanguage articles. Many of these articles show improved performance on simulation scenarios after practice. Recently, there is a growing body of evidence that simulation may lead to improved clinical outcomes. ${ }^{11}$ 
Tables 2 and 3 show an attempt to create a framework for the characterization of levels of evidence for obstetric simulation and the current state of that evidence for some clinical scenarios. As suggested in Table 3, simulation of a shoulder dystocia at the time of vaginal delivery has evolved from a mere teaching tool to a method to decrease neonatal morbidity. Deering at $\mathrm{al}^{12}$ reported that training with a simulation scenario improved residents' performance in the management of shoulder dystocia that included timeliness of interventions, performance of maneuvers, and overall technical performance. Crofts et $\mathrm{al}^{6}$ evaluated the effectiveness of high- vs lowfidelity manikins for shoulder dystocia simulation. They found that all training with manikins improved the management of simulated shoulder dystocia, but training on a high-fidelity manikin, which included force perception teaching, offered additional training benefits.

Analysis of filmed shoulder dystocia simulations revealed that failure to achieve delivery was associated with failure to get the whole hand in vagina. ${ }^{13}$ At our institutions, we use shoulder dystocia simulations to teach and review key elements in documentation. ${ }^{14}$ Furthermore, we record all scenarios and review the recordings with our trainees. Finally, Draycott et $\mathrm{al}^{11}$ compared the management of neonatal injury that is associated with shoulder dystocia before and after the introduction of mandatory shoulder dystocia simulation training. There was a significant reduction in neonatal injury at birth after shoulder dystocia: 30 of 324 procedures $(9.3 \%)$ to 6 of 262 procedures $(2.3 \%$; relative risk, 0.25 ; $95 \%$ confidence interval, 0.11-0.57). Thus, obstetric simulation for shoulder dystocia has proved valuable at multiple levels that include educating relatively inexpe- rienced learners, allowing experienced providers to maintain infrequently used skills, and improving patient safety by decreasing neonatal morbidity. As more experience is gained with simulation, it stands to reason that the level of evidence for other obstetric simulations will increase as well.

\section{Comment}

Our major professional organizations have dedicated resources to obstetric simulation development. Table 4 provides a list of academic and commercial resources that can be helpful to those health care providers who are attempting to set up obstetric simulation programs. The ACOG Simulation Consortium has assembled a group of experts to work on optimizing simulations for obstetric residents; the Society for Maternal-Fetal Medicine has established a subcommittee to share experience and conduct postgraduate courses in simulation for maternal-fetal medicine; and the Society of Simulation in Healthcare has established an obstetrics and gynecology interest group to share information. Simulation in obstetrics allows us to practice in a safe environment. It enables us to practice and make mistakes while causing no harm to patients. The evidence is overwhelming that, with practice, obstetricians improve their technical and communication skills. Evidence is emerging that simulation ultimately may improve maternal and neonatal outcomes. It stands to reason that simulation in obstetrics should be incorporated into comprehensive patient safety programs.

\section{REFERENCES}

1. Pettker CM, Thung SF, Norwitz ER, et al. Impact of a comprehensive patient safety strategy on obstetric adverse events. Am J Obstet Gynecol 2009;200:492.e1-8.
2. Pronovost PJ, Holzmueller CG, Ennen CS, Fox HE. Overview of progress in patient safety. Am J Obstet Gynecol 2011;204:5-10.

3. Goffman D, Heo H, Pardanani S, et al. Improving shoulder dystocia management among resident and attending physicians using simulations. Am J Obstet Gynecol 2008;199: 294.e1-7.

4. Dupuis O, Moreau R, Silveira R, et al. A new obstetric forceps for training junior doctors: a comparison of the spatial dispersion of forceps blade trajectories between junior and senior obstetricians. Am J Obstet Gynecol 2006;194: 1524-31.

5. Dupuis O, Moreau R, Pham MT, Redarce T. Assessment of forceps blade orientations during their placement using an instrumented childbirth simulator. BJOG 2009;116:327-33.

6. Crofts JF, Bartlett C, Ellis D, et al. Training for shoulder dystocia. Obstet Gynecol 2006;108: 1477-85.

7. Leslie KK, Dipasquale-Lehnerz P, Smith M. Obstetric forceps training using visual feedback and isometric strength testing unit. Obstet Gynecol 2005;105:377-82.

8. Ellis D, Crofts JF, Hunt L, et al. Hospital, simulation center, and teamwork training for eclampsia management. Obstet Gynecol 2008; 111:723-31.

9. Crofts JF, Bartlett RM, Ellis, RM, Hunt LP, Fox R, Draycott TJ. Management of shoulder dystocia skill retention 6 and 12 months after training. Obstet Gynecol 2007;110:1069-74.

10. Maslovitz S, Barkai G, Lessing JB, Ziv A, Many A. Recurrent obstetric management mistakes identified by simulation. Obstet Gynecol 2007;109:1295-300.

11. Draycott TJ, Crofts JF, Ash JP, et al. Improving neonatal outcome through practical shoulder dystocia training. Obstet Gynecol 2008;112:14-20.

12. Deering S, Poggi S, Macedonia C, Gherman R, Satin AJ. Improving resident competency in the management of shoulder dystocia with simulation training. Obstet Gynecol 2004; 103:1224-8.

13. Crofts JF, Fox R, Ellis D, et al. Observations from 450 shoulder dystocia simulations: lessons for skills training. Obstet Gynecol 2008; 112:906-12.

14. Deering S, Poggi S, Hodor J, Macedonia C, Satin AJ. Evaluation of residents' delivery notes after a simulated shoulder dystocia. Obstet Gynecol 2004;104:677-70. 